\title{
A GREAT RANGE OF SMALL EQUIPMENT
}

The Dental Directory has a great range of small equipment, all with the latest designs to conform to best practice guidelines for decontamination. An excellent example of this is the Ultrawave Hygea 1250VP ultrasonic cleaning bath 8L, now on offer at The Dental Directory.

Combining excellent performance with a modern design and enhanced features, the Ultrawave Hygea gives excellent cleaning results on reusable surgical instruments cycle after cycle. It includes an LCD control panel programmer which enables user programmable cycle parameters, and an integral validation printer. Complete with split level security features, the Hygea also has a thermostatic cut out, easy drain valve, electromagnetic locking lid and a three tray basket system inside.

Reader response number 57

\section{HIGH QUALITY MAGNIFICATION}

Dental professionals have come to associate Hogies with high quality eye protection, illumination and magnification. The stylish, long lasting Hogies frames fix to loupes, auxiliary illumination and prescription lenses with straightforward and effective magnetic connectors.

Hogies MiniScope Loupes are available with $2.5 \times$ or $3 \times$ magnification and provide the wearer with an uninterrupted field of vision, depth of field and a working distance of $420 \mathrm{~mm}$ to promote the most comfortable posture. The MiniScope is lightweight, easily adjustable and reduces strain for the wearer during treatment.

With Hogies Visors, the wearer enjoys full-face protection from the debris and bio-aerosols that can result from clinical procedures. The Visors are adjustable and cater for most eye- glass prescriptions. Each Visor comes complete with 10 disposable shields, with replacement shields available in packs of 10. The Visors come in seven fresh and vibrant colours to integrate perfectly with your practice colour scheme.

The Hogies range is designed to precise specifications, providing the dental professional with the highest standard of equipment.

\section{Reader response number 58}

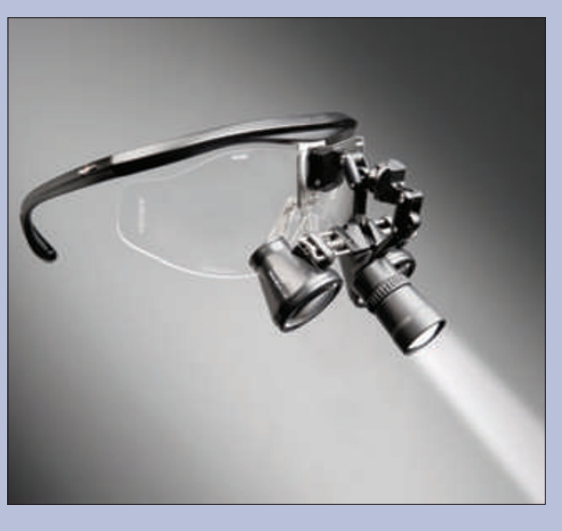

\section{THE FINANCIAL CHOICE}

When running a private practice you want to be using the most up-to-date surgery equipment, but keeping up with modern technology and maintaining a modern practice can come with a hefty price tag.

The team at Henry Schein Minerva are highly knowledgeable and experienced in offering the best, most practical advice on how to grow and improve your practice within your budget through their Financial Services Division, ChoiceHealth Leasing.

ChoiceHealth Leasing has been created to present options that may not have been possible before and will help you manage your finances and fund practice growth, with solutions for leasing, lease purchasing, hire purchase and borrowing issues. This coupled with our extremely competitive rates means that better, more advanced equipment can be yours without additional monetary stresses and strains.

With ChoiceHealth Leasing's trained and experienced consultants at your side you can feel safe in the knowledge that you'll receive the most cost-effective and tax efficient way of funding your practice equipment purchases, and all with minimal stress.

Reader response number 59 